Published in final edited form as:

Br J Sports Med. 2019 November ; 53(21): 1333-1340. doi:10.1136/bjsports-2016-097261.

\title{
'What's my risk of sustaining an ACL injury while playing football (soccer)?' A systematic review with meta-analysis
}

\author{
Alicia M Montalvo ${ }^{1}$, Daniel K Schneider ${ }^{2,3}$, Paula L Silva ${ }^{4}$, Laura Yut ${ }^{5}$, Kate E Webster ${ }^{6}$, \\ Michael A Riley ${ }^{4}$, Adam W Kiefer ${ }^{2,4,7}$, Jennifer L Doherty-Restrepo ${ }^{1}$, Gregory D Myer ${ }^{7,8,9,10}$ \\ ${ }^{1}$ Department of Athletic Training, Florida International University, Nicole Wertheim College of \\ Nursing and Health Sciences, Miami, Florida, USA \\ ${ }^{2}$ Department of Pediatrics, College of Medicine, University of Cincinnati, Cincinnati, Ohio, USA \\ ${ }^{3}$ College of Medicine, University of Cincinnati, Cincinnati, Ohio, USA \\ ${ }^{4}$ Center for Cognition, Action, \& Perception, Department of Psychology, University of Cincinnati, \\ Cincinnati, Ohio, USA \\ ${ }^{5}$ Department of Biostatistics, Robert Stempel School of Public Health and Social Work, Florida \\ International University, Miami, Florida, USA \\ ${ }^{6}$ School of Allied Health, College of Science, Health and Engineering, La Trobe University, \\ Melbourne, Australia \\ ${ }^{7}$ Division of Sports Medicine, Cincinnati Children's Hospital Medical Center, The SPORT Center, \\ Cincinnati, Ohio, USA \\ ${ }^{8}$ Departments of Pediatrics and Orthopaedic Surgery, University of Cincinnati, Cincinnati, Ohio, \\ USA \\ ${ }^{9}$ The Micheli Center for Sports Injury Prevention, Waltham, Massachusetts, USA \\ ${ }^{10}$ Department of Orthopaedics, University of Pennsylvania, Philadelphia, Pennsylvania, USA
}

\begin{abstract}
Objective-To estimate the incidence proportion (IP) and incidence rate (IR) of ACL injury in football players.

Design-Systematic review with meta-analysis.

Data sources-PubMed, CINAHL and SPORTDiscus electronic databases were searched from inception to 20 January 2017.
\end{abstract}

\footnotetext{
Correspondence to: Dr Gregory D Myer, Division of Sports Medicine, Cincinnati Children's Hospital Medical Center, The SPORT Center, Cincinnati OH 45229, USA; greg.myer@cchmc.org.

Contributors All authors contributed significantly to the conception, design and writing of this manuscript.

Competing interests None declared.

Patient consent Not required.

Provenance and peer review Not commissioned; externally peer reviewed.

Data sharing statement All data in this review are available in the journal in which they were published.
} 
Eligibility criteria for selecting study-Studies that reported the total number of participants/ population by sex, total number of ACL injuries by sex and total person-time by sex were included.

Results-Twenty-eight studies were included. The IP and IR of ACL injury in female football players were $2.0 \%$ (95\% CI $1.2 \%$ to 3.1\%) and 2.0/10 000 athlete exposures (AEs) (95\% CI 1.6 to 2.6; $\mathrm{I}^{2}=91 \%$ ) over a period of one season to 4 years. The IP and IR of ACL injury in male players were $3.5 \%$ (95\% CI $0.7 \%$ to $8.2 \%$ ) and $0.9 / 10000 \mathrm{AEs}\left(95 \%\right.$ CI 0.7 to $1.1 ; \mathrm{I}^{2}=94 \%$ ). Studies that evaluated matched cohorts of female and male players showed no difference in IP (relative risk $=1.2 ; 95 \% \mathrm{CI} 0.9$ to $1.6 ; \mathrm{P}=0.47$ ) over a period of one season to 4 years. Women were at greater risk than men (incidence rate ratio $(\mathrm{IRR})=2.2 ; 95 \% \mathrm{CI} 1.6$ to $3.1 ; \mathrm{I}^{2}=83 \% ; \mathrm{P}<0.001$ ). When accounting for participation level, the difference in IR between women and men was greatest for intermediate players (IRR $=2.9 ; 95 \%$ CI 2.4 to 3.6) compared with amateur (IRR=2.6; 95\% CI 1.4 to 4.8 ) and elite (IRR=2.0; $95 \%$ CI 1.1 to 3.4 ) players.

Summary/conclusion-Overall, more men sustained ACL injury in football. There was no difference in the relative risk of ACL injury between female and male football players in a window that spanned one season to 4 years. The IR of ACL injury among women was 2.2 times higher than the IR of ACL injury among men. The reported sex disparity in ACL injury was independent of participation level.

\section{INTRODUCTION}

ACL rupture is one of the most serious injuries associated with participation in football (soccer). ${ }^{12}$ ACL injury can have serious consequences for activity level and quality of life. ${ }^{34}$ Many athletes with ACL injury do not return to full sport participation, gain weight, and develop degenerative knee conditions, such as osteoarthritis, later in life.$^{5-7}$

Female football players may have a higher risk of these problems than their male counterparts. ${ }^{89}$ This sex disparity requires attention from the sports medicine community because of the increasing popularity of football among women. The number of women playing football increased from the 26 million reported in the most recent Big Count survey in 2006 to over 30 million reported in the Women's Football Survey in $2014 .{ }^{1011}$ In addition, programmes with the goal of further increasing women's participation were announced in the last Women's Football Symposium. ${ }^{12}$ To safely achieve this goal requires actions to attract women to football and foster their successful, long-term participation. For the latter, addressing sex disparities in the risk for serious injuries, such as ACL rupture, is key.

Previous studies in collegiate athletes estimated that female football players were at approximately three times the risk of sustaining ACL injury relative to male soccer players from 1989 to 1993 , from 1989 to 2002 and from 1989 to $2004 .{ }^{13-15}$ A 2007 meta-analysis estimated that the incidence rate (IR) of ACL injury was more than 2.5 times higher among female football players relative to male football players. ${ }^{8}$ Most studies included in this metaanalysis documented ACL injuries in college-level football players. It is not clear whether participation level influenced the documented sex differences in ACL injury IR. The sex differences in incidence proportion (IP; number of new injuries relative to total number of athletes exposed) seem to be less pronounced. ${ }^{9}$ A possible reason is that the participation of 
female football players has been historically characterised by fewer training sessions and games, but that difference is rapidly changing. ${ }^{10-12}$ In the last 10 years, there have been no additional systematic reviews or meta-analyses aggregating available studies. The aims of this systematic review were to: (1) provide current, pooled estimates of IP and IR of ACL injury in female and male football and (2) evaluate whether sex differences in ACL injury were affected by participation level.

\section{METHOD}

A systematic review was conducted using the Preferred Reporting Items for Systematic Reviews and Meta-Analyses guidelines. We searched the PubMed and EBSCO host (CINAHL, SPORTDiscus) electronic databases from database inception to 20 January 2017. We used the search phrase: anterior cruciate ligament AND (injury OR tear OR rupture) AND (incidence OR prevalence OR epidemiology). The terms soccer and football were not used because this search was also used in a larger meta-analysis that included all sports. ${ }^{16}$ The articles pertinent to football were selected for this meta-analysis. We limited the search to peer-reviewed articles published in English language. Experts in the field were contacted for further study suggestions, and references from review papers were examined to identify any further relevant articles for potential inclusion. Publication details from all studies identified in the literature search were exported to bibliographic software (EndNote X7, Thomson Reuters, USA).

\section{Selection criteria}

One assessor screened articles for inclusion. Any grey areas of inclusion were brought to discussion with the second assessor, and any disagreements were arbitrated by a third assessor. Articles were screened first by title, then by abstract and finally by full text according to the inclusion and exclusion criteria (box 1). Full texts were retrieved when the title or abstract met the selection criteria, or when the status (include or exclude) could not be determined from the title and/or abstract alone.

\section{Data extraction and management}

The primary variables extracted were the number of ACL injuries, exposure for men and exposure for women and participation level (amateur, intermediate or elite). The amateur category included recreational, amateur and high school football players. ${ }^{17-25}$ The intermediate category included collegiate and upper division amateur football players. 172226-28 The elite category included professional and elite football players. ${ }^{29-36}$ One author recorded all of the pertinent data from the included articles and another author independently reviewed those data for accuracy and completeness. The studies included in the IP and IR analyses are listed in online supplementary file 1.

The reported person-time unit was not uniform across studies. To establish a common metric, we calculated athlete exposure (AE). When the number of player-hours was reported, AEs were estimated by multiplying the number of player-hours by two. ${ }^{2024253032-3537-40}$ This was to estimate the average length of training sessions and games with warm-ups included. Play-er-days were treated as AEs as athletes typically participate in one training 
session or game per day. This unit was only used in studies that investigated high school and college athletes. ${ }^{17}$ For studies that reported IR by sex, the number of AEs and the reported IRs were used to calculate the number of ACL injuries by sex (number of ACL injuries by sex=total AE by sex $\times$ rate numerator by sex/rate denominator by sex). ${ }^{21}$

Whenever possible, the IP and IR were calculated. The IP was calculated by dividing the number of new ACL injuries by the total number of participants over the given time period specified in each study. The denominator for IP ranged from one season to 4 years. The IR was calculated by dividing the total number of new ACL injuries by the total number of exposures. We emailed the authors of studies where the number of ACL injuries by sex could not be estimated. If the study authors did not have access to the information or did not respond to our email, the study was excluded from the meta-analysis. ${ }^{1941-43}$

\section{Risk of bias assessment}

Risk of bias was assessed by two authors independently using the Quality Assessment Tool for Observational Cohort and Cross-Sectional Studies. ${ }^{44}$ This tool dichotomously assesses criteria including participation rate, whether exposure data were collected prospectively, whether the timeframe was sufficient to allow for the outcome to occur and number of participants lost to follow-up after baseline. If the criterion was present, the item was given a ' $\mathrm{Y}$ '. If the criterion was absent or was not reported, the item was given an ' $\mathrm{N}$ '. Any discrepancies in assessment were discussed. For discrepancies that could not be resolved, a third author was consulted for arbitration. Studies where interventions were administered were treated as cohort studies in our analyses and assessed using the same tool. Studies that fulfilled fewer than $50 \%$ of criteria were deemed to be of low quality.

\section{Statistical analysis}

Injury data were analysed using R (V3.3.2, the R Foundation for Statistical Computing). We used the packages meta and metafor with the functions metarate for IR, metaprop for IP single ratio, metainc for incidence rate ratio (IRR) and metabin for IP binary data ratio (weighted for individual study size). When the number of ACL injuries was zero, 0.1 was substituted so the measure could be used in meta-analysis. For calculating IP and IR for the total population, female football players only and male football players only, all studies that presented data were included in the respective analyses. When calculating the relative risks (RRs) and IRRs, only studies that included men and women in the same study were used. For example, studies that included only women were used to calculate female IP and IR, but were not used to calculate RR or IRR .

Injury risk proportions for individual studies and pooled estimates were summarised in forest plots for the following subgroups: woman, man and combined. A pooled estimate for the RR of ACL injury in women compared with men was calculated and summarised in a forest plot. Raw injury IRs for individual studies and pooled estimates were summarised in forest plots for the following groups and subgroups: woman, man and combined. Pooled IRRs for women compared with men were calculated and summarised in forest plots. Heterogeneity was assessed using the $\mathrm{I}^{2}$ statistic, ${ }^{45}$ which estimates the variation resulting from heterogeneity and not chance. ${ }^{45} \mathrm{I}^{2}$ values over $75 \%$ were considered high. ${ }^{45}$ 
Publication bias was assessed using funnel plots with SE as the measure of the study size on the $y$ axis and the ratio on the $x$ axis. A $P$ value of $₫ 0.05$ was considered significant for all statistical analyses.

\section{Sensitivity analyses}

To account for heterogeneity among studies, we used sensitivity analysis to assess the effect of each individual study on the overall rate of ACL injury. This was done by removing one study, performing the analysis, investigating the effect of the removal on heterogeneity, returning the study to the analysis and repeating the procedure. This was repeated for each main analysis.

To account for bias, we attempted to perform separate analyses on studies that met the criteria for item 11 (reliability and validity of measurement of the dependent variable) and item 14 (statistical adjustment for potential confounding variables). However, there were too few studies that met the criteria. Therefore, we included all studies in the final analysis (regardless of heterogeneity), and we expected that combining sports with varying risks of ACL injury would result in high heterogeneity.

\section{Subgroup analyses}

To account for differences in participation levels, we compared IRs from amateur, intermediate and elite athletes. To identify changes in the rates of ACL injury since the rates established in $2007,{ }^{8}$ we calculated rates in studies published after 2007.

\section{RESULTS}

The final search yielded 3774 abstracts. After removal of duplicates, there were 1300 records. After title and abstract screening, 1155 articles were excluded. The remaining 145 articles were manually cross-referenced, and experts were consulted to identify additional relevant articles, resulting in the inclusion of a further 17 articles. We screened the full-text articles of 162 articles, and 28 studies were included (figure 1 and online supplementary file $1)$.

\section{Risk of bias assessment}

Three studies fulfilled $75 \%$ or more of the criteria, and 23 studies fulfilled $50 \%$ or more of the criteria (online supplementary file 2). Five studies fulfilled fewer than $50 \%$ of the criteria and were deemed to be of low quality. It is possible that some studies may have been judged as being at high or moderate risk of bias simply because they did not report particular information, including the number of eligible individuals, how outcomes were measured and attrition.

The pooled ACL injury IP for all football players was $2.7 \%$ (95\% CI $1.6 \%$ to $4.1 \%$; $\mathrm{I}^{2}=98 \%$; figure 2). The pooled ACL injury IP for female football players was $2.0 \%$ (95\% CI $1.2 \%$ to $3.1 \%$; $\mathrm{I}^{2}=97 \%$; figure 3 ). The pooled ACL injury IP for male football players was $3.5 \%$ ( $95 \%$ CI $0.7 \%$ to $8.2 \% ; \mathrm{I}^{2}=99 \%$; figure 4 ). In studies that included only women or only men, the IP was greater in men than in women. However, we found that female and male football 
players were at equal risk for injury $\left(\mathrm{RR}=1.2 ; 95 \% \mathrm{CI} 0.9\right.$ to $1.6 ; \mathrm{I}^{2}=0 \% ; \mathrm{P}=0.47$; figure 5). A list of studies used for each analysis are located in online supplementary file 1.

ACL injury incidence among all football players was 1.7/1000 AEs (95\% CI 1.4 to $2.1 ; \mathrm{I}^{2}=$ 93\%; figure 6). Injury incidence among women was $2.0 \mathrm{ACL}$ injuries per $10000 \mathrm{AEs}(95 \%$ CI 1.6 to 2.6; $\mathrm{I}^{2}=91 \%$; figure 7), and injury incidence among men was 0.9 ACL per 10000 AEs (95\% CI 0.7 to $1.1 ; \mathrm{I}^{2}=94 \%$; figure 8 ). When controlling for exposure, women had a 2.2-fold increase in IR of ACL injury relative to men (IRR $=2.2 ; 95 \%$ CI 1.6 to $3.1 ; \mathrm{I}^{2}=$ $83 \%$; $\mathrm{P}<0.001$; figure 9).

The IRR was highest for intermediate players (IRR=2.9; 95\% CI 2.4 to 3.6). The IRR was lower for amateur (IRR=2.6; 95\% CI 1.4 to 4.8 ) and elite (IRR=2.0; 95\% CI 1.1 to 3.4 ) players (Figure 10).

The subgroup analysis of studies published after 2007 indicates that the IRR has remained stable over time (IRR=2.5; 95\% CI 2.1 to 3.02 ; figure 11$)$.

\section{Sensitivity analyses}

Excluding single studies from each analysis did not alter the statistical heterogeneity ( $\mathrm{I}^{2}$ statistic). Heterogeneity remained high (greater than $75 \%$ ) throughout the procedure. Excluding studies that did not fulfil item 11 in the risk of bias assessment did not statistically alter the pooled estimates for ACL injury incidence, and heterogeneity remained high. Excluding studies that did not fulfil item 14 in the risk of bias assessment did not statistically alter the pooled estimates for total ACL IR and female ACL injury IR. There were insufficient studies to conduct sensitivity analyses (excluding studies that did not fulfil item 14) for the other ACL injury outcomes.

\section{Publication bias}

The funnel plot for RR indicated that almost all studies fell within the expected parameters, most with low SE indicating that most studies were large (online supplementary file 3). A majority of studies reported that women had greater IP than men. The funnel plot for IRR indicated that most studies fell within the expected parameters (online supplementary file 4). SE was relatively low, indicating that studies were large, and a majority of studies reported that women were at increased risk of ACL injuries relative to men. The studies are not evenly distributed in the funnel, with studies missing from the lower left quadrant. Studies in the lower left quadrant would represent smaller studies that report a greater IP or IR of ACL injuries in men compared with women.

\section{DISCUSSION}

The IP and IR of ACL injury in female football players were $2.0 \%$ (95\% CI $1.2 \%$ to $3.1 \%$ ) and 2.0/10 $000 \mathrm{AEs}$ (95\% CI 1.6 to 2.6; $\mathrm{I}^{2}=91 \%$ ) over a period of one season to 4 years, respectively. The IP and IR of ACL injury in male football players were $3.5 \%$ (95\% CI 0.7\% to $8.2 \%$ ) and $0.9 / 10000$ AEs (95\% CI 0.7 to $1.1 ; \mathrm{I}^{2}=94 \%$ ), respectively. Female football players had a similar ACL injury IP to male football players. Female football players had a 2.2-fold increase in the IR of ACL injury compared with men. Women remained at greater 
risk of ACL injury regardless of participation level, suggesting that injury risk may be independent of participation level. The IRR identified in our review (2.50) is similar to previous research (2.67). ${ }^{8}$

We aimed to answer the following questions: (1) what are the IP and the IR of ACL injuries for all football players, female football players and male football players? and (2) are there sex differences in IP and IR of ACL injuries? When pooling data to answer our review questions, there was a trade-off between including more studies and producing spurious estimates when pooling statistically and clinically heterogeneous data. We did not exclude studies based on either risk of bias or level of evidence, and we judged the risk of bias in included studies as moderate because most included studies (23/28) met 50\% or more of the criteria. Many criteria that were not met were not relevant to epidemiological study quality, but the large number of included studies may enhance the generalisability of our results. Based on the Centre for Evidence Based Medicine, these estimates could be judged as level 4 evidence (Grade of Recommendation, C). ${ }^{46}$ With regard to publication bias, there were few studies published indicating that men were at greater risk of sustaining ACL than women. While it is possible that this dearth is due to publication bias, it seems more likely that most studies tend to find that women are at greater risk of sustaining ACL injury than men. Therefore, we deem that publication bias is low.

While we found a difference in the IR of ACL injury between men and women, we did not find a difference in IP This contrasts with previous research. ${ }^{9}$ IR is the rate of new injuries, and IP is the number of newly injured individuals. If the rate at which ACL injury occurs is more than twice as high in women, it seems reasonable to expect that a higher proportion of women would sustain this injury than men. However, this assumes that exposure is similar between men and women. The higher IR of ACL injury among female athletes associated with the absence of sex effects on IP suggests that men have greater exposure than women (ie, men participate in more training sessions and games). Given the number of female sports teams is increasing, the difference in participation rates between men and women might be expected to reduce. ${ }^{10-12}$ An increase in the number of championships, games per championship and training sessions played by women is also likely. Therefore, an increase in IP among female football players may follow.

Among football players, women had a 2.2 times greater incidence of ACL injury compared with men. Our estimate of the ACL IR for female football players was 2.5, which is similar to previous research. The fact that the IR among female football players has remained steady, despite increasing evidence of the effectiveness of injury prevention interventions, is disappointing. Even with increased knowledge about injury prevention, we did not find evidence that the incidence of ACL injury in female football players has reduced. ${ }^{47-49}$ The disparity between the effects of intervention studies and injury outcomes in female athletes highlights the need to bridge the gap between scientific advances about ACL injury prevention and clinical practice. If primary ACL injury prevention programmes are effective, then the challenge becomes to identify and overcome factors that may be limiting the clinical application of scientific evidence. 
Effective prevention programmes require substantial resources and time commitments. These programmes require intervention providers to supervise athletes to ensure correct technique and can be perceived as time-consuming. ${ }^{215051}$ Care must be taken in designing, implementing and encouraging adherence to prevention programmes to ensure prophylactic effects. ${ }^{405253}$ Even where these factors are taken into consideration, the most effective prevention programmes are associated with a high number needed to treat. ${ }^{54}$ Optimistic estimates suggest that 108 athletes have to be treated to prevent one ACL injury. ${ }^{54}$ Therefore, these programmes may have greatest value when a large population of football players is considered.

\section{Methods issues}

There are three issues related to systematic review methods that must be considered when reading and using the results of our systematic review. ${ }^{16}$

Risk of bias assessment-Poor internal validity (bias within studies) may have contributed to statistical heterogeneity. The tools available to assess risk of bias in observational (epidemiological) studies evaluate criteria that do not necessarily contribute to bias. For example, existing tools assess for randomisation of subjects, but this criterion is not relevant for prognosis studies. Items like this negatively impact risk of bias even though they are irrelevant to the study design or research question. Despite the limitations regarding the assessment of risk of bias, there was bias in included studies. Bias was not further reduced when investigating football alone relative to investigating all sports combined. ${ }^{16}$ Therefore, caution should be exercised in generalising rates and risks.

Sources of variability-The high $\mathrm{I}^{2}$ statistics in our analyses indicate that the variability in injury rates was due to heterogeneity rather than to chance. Heterogeneity remained high in studies investigating football alone relative to studies investigating a range of sports. ${ }^{16}$ There are at least three possible explanations for high heterogeneity in our review: (1) including a variety of study designs, including randomised controlled trials and cohort studies, (2) variable exposure data and estimating missing exposure for some studiesconversion of play- er-days and player-hours to AEs may have resulted in an underestimate of the true exposure which would contribute to an overestimation of the IRs and (3) differences in participation level.

Sensitivity and subgroup analyses-We used sensitivity and subgroup analyses based on participation level to explore potential sources of heterogeneity. However, statistical heterogeneity remained high in all sensitivity and subgroup analyses. We were unable to identify the main sources of statistical heterogeneity, and this reduces the robustness of the estimates in our systematic review.

\section{Limitations}

IPs and rates may have been overestimated by the inclusion of reinjuries. However, the inclusion of reinjuries is likely a small source of bias. Some studies only included noncontact mechanisms of injury. Therefore, the estimates provided here may be underestimates 
of the true rates, although it is difficult to be certain. IRs were based on estimated exposure for 18 of 38 studies included for rate analyses.

We did not assess the influence of age on the injury estimates because many studies did not specify participant age or age range. Controlling for age would have substantially reduced the number of studies eligible for inclusion. While the search was systematic and comprehensive, we acknowledge the risk for publication and language bias.

Future research-Whenever possible, future research should investigate injury epidemiology in male and female athletes simultaneously to allow for sex comparisons in future meta-analyses. This research should use the most specific exposure units possible, such as player-hours, and should detail exact length of follow-up in months or years. Because sport season lengths can vary by location, age and participation level, detailing follow-up length this way is particularly important for standardising the period of time over which exposures are occurring.

\section{CONCLUSION}

Female football players had 2.2-fold increase in the IR of ACL injury relative to male football players over 4 years. The sex difference in ACL injury rates was independent of participation level.

\section{Supplementary Material}

Refer to Web version on PubMed Central for supplementary material.

\section{Acknowledgments}

Funding We acknowledge funding support from the National Institutes of Health/ NIAMS Grant R21AR065068I01A1 and U01AR067997.

\section{REFERENCES}

1. Engström B, Johansson C, Törnkvist H. Soccer injuries among elite female players. Am J Sports Med 1991;19:372-5. [PubMed: 1897651]

2. Rochcongar P, Laboute E, Jan J, et al. Ruptures of the anterior cruciate ligament in soccer. Int J Sports Med 2009;30:372-8. [PubMed: 19199222]

3. Gottlob CA, Baker CL. Anterior cruciate ligament reconstruction: socioeconomic issues and cost effectiveness. Am J Orthop 2000;29:472-6. [PubMed: 10890463]

4. Gottlob CA, Baker CL, Pellissier JM, et al. Cost effectiveness of anterior cruciate ligament reconstruction in young adults. Clin Orthop Relat Res 1999;367:272-82.

5. Engström B, Forssblad M, Johansson C, et al. Does a major knee injury definitely sideline an elite soccer player? Am J Sports Med 1990;18:101-5. [PubMed: 2301681]

6. Myer GD, Faigenbaum AD, Foss KB, et al. Injury initiates unfavourable weight gain and obesity markers in youth. Br J Sports Med 2014;48:1477-81. bjsports-2012-091988. [PubMed: 23673521]

7. Kessler MA, Behrend H, Henz S, et al. Function, osteoarthritis and activity after ACL-rupture: 11 years follow-up results of conservative versus reconstructive treatment. Knee Surg Sports TraumatolArthrosc 2008;16:442-8. 
8. Prodromos CC, Han Y, Rogowski J, et al. A meta-analysis of the incidence of anterior cruciate ligament tears as a function of gender, sport, and a knee injury-reduction regimen. Arthroscopy 2007;23:1320-5. [PubMed: 18063176]

9. Waldén M, Hägglund M, Werner J, et al. The epidemiology of anterior cruciate ligament injury in football (soccer): a review of the literature from a gender-related perspective. Knee Surg Sports Traumatol Arthrosc 2011;19:3-10. [PubMed: 20532868]

10. Fédération Internationale de Football Association (FIFA) 2008http://www.fifa.com/mm/document/ fifafacts/bcoffsurv/bigcount.statspackage_7024.pdf

11. Fédération Internationale de Football Association (FIFA) 2014http://www.fifa.com/mm/document/ footballdevelopment/women/02/52/26/49/womensfootballsuivey2014_e_english.pdf

12. FIFA Women's Football Symposium: FIFA. 2015http://www.fifa.com/womensworldcup/news/ $\mathrm{y}=2015 / \mathrm{m}=5 /$ news $=$ vi-fifa-women-s-football-symposium-2609122.html

13. Arendt E, Dick R. Knee injury patterns among men and women in collegiate basketball and soccer. NCAA data and review of literature. Am J Sports Med 1995;23:694-701. [PubMed: 8600737]

14. Agel J, Arendt EA, Bershadsky B. Anterior cruciate ligament injury in national collegiate athletic association basketball and soccer: a 13-year review. Am J Sports Med 2005;33:524-31. [PubMed: 15722283]

15. Mihata LC, Beutler AI, Boden BP. Comparing the incidence of anterior cruciate ligament injury in collegiate lacrosse, soccer, and basketball players: implications for anterior cruciate ligament mechanism and prevention. Am J Sports Med 2006;34:899. [PubMed: 16567461]

16. Montalvo AM, Schneider DK, Yut L, et al. What's my risk of sustaining an ACL injury while playing sports? A systematic review with meta-analysis. Br J Sports Med. In Press. 2018:bjsports-2016-096274.

17. Beynnon BD, Vacek PM, Newell MK, et al. The Effects of Level of Competition, Sport, and Sex on the Incidence of First-Time Noncontact Anterior Cruciate Ligament Injury. Am J Sports Med 2014;42:1806-12. [PubMed: 25016012]

18. Hewett TE, Myer GD, Ford KR, et al. Biomechanical measures of neuromuscular control and valgus loading of the knee predict anterior cruciate ligament injury risk in female athletes: a prospective study. Am J Sports Med 2005;33:492-501. [PubMed: 15722287]

19. Joseph AM, Collins CL, Henke NM, et al. A multisport epidemiologic comparison of anterior cruciate ligament injuries in high school athletics. JAthl Train 2013;48:810-7. [PubMed: 24143905]

20. Kiani A, Hellquist E, Ahlqvist K, et al. Prevention of soccer-related knee injuries in teenaged girls. Arch Intern Med 2010;170:43. [PubMed: 20065198]

21. Mandelbaum BR, Silvers HJ, Watanabe DS, et al. Effectiveness of a neuromuscular and proprioceptive training program in preventing anterior cruciate ligament injuries in female athletes: 2-year follow-up. Am J Sports Med 2005;33:1003-10. [PubMed: 15888716]

22. Mountcastle SB, Posner M, Kragh JF, et al. Gender differences in anterior cruciate ligament injury vary with activity: epidemiology of anterior cruciate ligament injuries in a young, athletic population. Am J Sports Med 2007;35:1635. [PubMed: 17519438]

23. Pfeiffer RP, Shea KG, Roberts D, et al. Lack of effect of a knee ligament injury prevention program on the incidence of noncontact anterior cruciate ligament injury. J Bone Joint Surg Am 2006;88:1769-74. [PubMed: 16882900]

24. Steffen K, Myklebust G, Olsen OE, et al. Preventing injuries in female youth football-a clusterrandomized controlled trial. Scand J Med Sci Sports 2008;18:605-14. [PubMed: 18208428]

25. Waldén M, Atroshi I, Magnusson H, et al. Prevention of acute knee injuries in adolescent female football players: cluster randomised controlled trial. BMJ 2012;344:e3042. [PubMed: 22556050]

26. Gilchrist J, Mandelbaum BR, Melancon H, et al. A randomized controlled trial to prevent noncontact anterior cruciate ligament injury in female collegiate soccer players. Am J Sports Med 2008;36:1476-83. [PubMed: 18658019]

27. Gwinn DE, Wilckens JH, McDevitt ER, et al. The relative incidence of anterior cruciate ligament injury in men and women at the United States Naval Academy. Frequence relative des blessures du ligament croise anterieur chez des hommes et des femmes a l'Academie Navale des Etats-Unis. Am J Sports Med 2000;28:98. [PubMed: 10653551] 
28. Hootman JM, Dick R, Agel J. Epidemiology of collegiate injuries for 15 sports: summary and recommendations for injury prevention initiatives. JAthl Train 2007;42:311. [PubMed: 17710181]

29. Arnason A, Engebretsen L, Bahr R. No effect of a video-based awareness program on the rate of soccer injuries. Am J Sports Med 2005;33:77-84. [PubMed: 15611002]

30. Faude O, Junge A, Kindermann W, et al. Injuries in female soccer players: a prospective study in the German national league. Am J Sports Med 2005;33:1694. [PubMed: 16093546]

31. Hägglund M, Atroshi I, Wagner P, et al. Superior compliance with a neuromuscular training programme is associated with fewer ACL injuries and fewer acute knee injuries in female adolescent football players: secondary analysis of an RCT. Br J Sports Med 2013;47:974-9. [PubMed: 23962878]

32. Le Gall F, Carling C, Reilly T. Injuries in young elite female soccer players: an 8-season prospective study. Am J Sports Med 2008;36:276-84. [PubMed: 17932408]

33. Ostenberg A, Roos H. Injury risk factors in female European football. A prospective study of 123 players during one season. Scand J Med Sci Sports 2000;10:279-85. [PubMed: 11001395]

34. Tegnander A, Olsen OE, Moholdt TT, et al. Injuries in Norwegian female elite soccer: a prospective one-season cohort study. Knee Surg Sports TraumatolArthrose 2008;16:194-8.

35. Waldén M, Hägglund M, Magnusson H, et al. Anterior cruciate ligament injury in elite football: a prospective three-cohort study. Knee Surg Sports Traumatol Arthrose 2011;19:11-19.

36. Waldén M, Hägglund M, Orchard J, et al. Regional differences in injury incidence in European professional football. Scand J Med Sei Sports 2013;23:424-30.

37. Giza E, Mithöfer K, Farrell L, et al. Injuries in women's professional soccer. Br J Sports Med 2005;39:212-6. [PubMed: 15793089]

38. Hägglund M, Walden M, Ekstrand J. Injuries among male and female elite football players. Scand J Med Sei Sports 2009;19:819-27.

39. Krutsch W, Zeman F, Zellner J, et al. Increase in ACL and PCL injuries after implementation of a new professional football league. Knee Surg Sports Traumatol Arthrosc 2016;24:2271-9. [PubMed: 25293676]

40. Söderman K, Werner S, Pietilä T, et al. Balance board training: prevention of traumatic injuries of the lower extremities in female soccer players? Knee Surg Sports Traumatol Arthrosc 2000;8:35663. [PubMed: 11147154]

41. Bjordal JM, ArnJy F, Hannestad B, et al. Epidemiology of anterior cruciate ligament injuries in soccer. Am J Sports Med 1997;25:341-5. [PubMed: 9167814]

42. Mufty S, Bollars P, Vanlommel L, et al. Injuries in male versus female soccer players: epidemiology of a nationwide study. Acta Orthop Belg 2015;81:289-95. [PubMed: 26280969]

43. Ristolainen L, Heinonen A, Waller B, et al. Gender differences in sport injury risk and types of inju-ries: a retrospective twelve-month study on cross-country skiers, swimmers, long-distance runners and soccer players. J Sports Sci Med 2009;8:443. [PubMed: 24150009]

44. Quality Assessment Tool for Observational Cohort and Cross-Sectional Studies National Institutes of Health. http://www.nhlbi.nih.gov/health-pro/guidelines/in-develop/cardiovascular-riskreduction/tools/cohort

45. Higgins JP, Thompson SG, Deeks JJ, et al. Measuring inconsistency in meta-analyses. BMJ 2003;327:557-60. [PubMed: 12958120]

46. Oxford Centre for Evidence-based Medicine - Levels of Evidence. 2009 http://www.cebm.net/ oxford-centre-evidence-based-medicine-levels-evidence-march-2009/

47. Hewett TE, Ford KR, Myer GD. Anterior cruciate ligament injuries in female athletes: Part 2, a meta-analysis of neuromuscular interventions aimed at injury prevention. Am J Sports Med 2006;34:490. [PubMed: 16382007]

48. Yoo JH, Lim BO, Ha M, et al. A meta-analysis of the effect of neuromuscular training on the prevention of the anterior cruciate ligament injury in female athletes. Knee Surg Sports Traumatol Arthrosc 2010;18:824-30. [PubMed: 19760399]

49. Myer GD, Sugimoto D, Thomas S, et al. The influence of age on the effectiveness of neuromuscular training to reduce anterior cruciate ligament injury in female athletes: a metaanalysis. Am J Sports Med 2013;41:203-15. [PubMed: 23048042] 
50. Petersen W, Braun C, Bock W, et al. A controlled prospective case control study of a prevention training program in female team handball players: the German experience. Arch Orthop Trauma Surg 2005;125:614-21. [PubMed: 15703919]

51. Hewett TE, Lindenfeld TN, Riccobene JV, et al. The effect of neuromuscular training on the incidence of knee injury in female athletes. A prospective study. Am J Sports Med 1999;27:699_ 706. [PubMed: 10569353]

52. Heidt RS, Sweeterman LM, Carlonas RL, et al. Avoidance of soccer injuries with preseason conditioning. Am J Sports Med 2000;28:659-62. [PubMed: 11032220]

53. Sugimoto D, Myer GD, Bush HM, et al. Compliance with neuromuscular training and anterior cruciate ligament injury risk reduction in female athletes: a meta-analysis. J Athl Train 2012;47:714-23. [PubMed: 23182020]

54. Sugimoto D, Myer GD, McKeon JM, et al. Evaluation of the effectiveness of neuromuscular training to reduce anterior cruciate ligament injury in female athletes: a critical review of relative risk reduction and numbers-needed-to-treat analyses. Br J Sports Med 2012;46:979-88. [PubMed: 22745221] 


\section{Inclusion and exclusion criteria}

\section{Inclusion criteria}

- Research conducted in football

- Total number of ACL injuries and total number of individuals in the population by sex reported

- Reported data such that the number of ACL injuries by sex could be calculated.

\section{Exclusion criteria}

- Further analyses on previously reported studies

- Studies written in languages other than English

- Review articles. 


\section{What is known already known?}

- In 2007, the incidence rate ratio (IRR) of ACL injuries in women compared with men in football was estimated to be 2.7 .

\section{What are the new findings?}

- Female and male football players had similar ACL injury IP in a window that spanned one season and 4 years.

- The incidence rate of ACL injury among female football players over 4 years was 2.2 times higher than the incidence of ACL injury among male football players.

- The sex differences in ACL injury rates were independent of participation level.

- The IRR in football players has remained unchanged since 2007 (2.7 vs 2.5). 


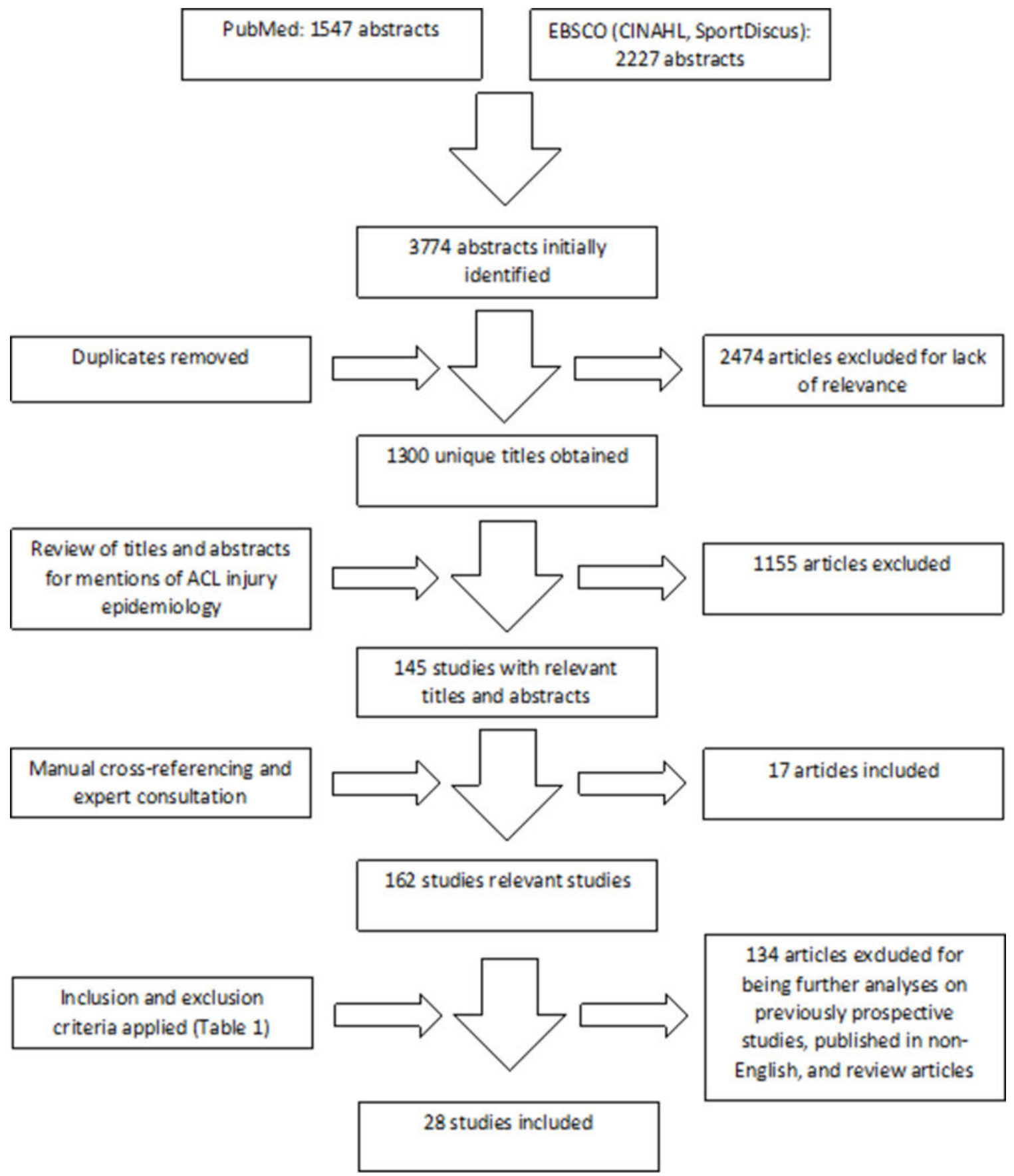

Figure 1.

Flow chart summary of the literature search process. 


\section{Author}

Caraffa et al,1996

Faude et al,2005

Gilchrist et al,2008

Giza et al,2005

Hagglund et al,2009

Heidt et al,2000

Kiani et al,2010

Krutsch et al,2016

LeGall et al,2008

Mandelbaum et al,2005

Ostenburg and Roos, 2000

Padua et al,2015

Pfeiffer et al,2006

Quisquater et al,2013

Rahnama et al,2009

Soderman et al,2000

Steffen et al,2008

Steffen et al,2016

Tegnander et al,2008

Walden et al,2011

Walden et al,2012

Random effects model

Heterogeneity: $I^{2}=98 \%, \tau^{2}=0.0069, p<0.01$

Total Number of ACL Injuries Total Population

80
11
25
8
16
9
5
16
12
73
5
7
1
608
33
5
9
29
2
21
35

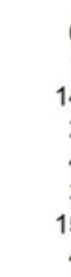

6
165
1435
2
4
3
15
400
4

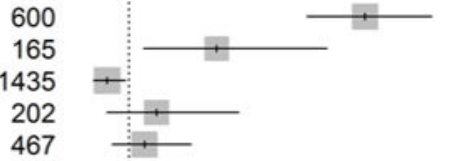

300

408
119

119
5703

5703
123

829

$433+$

833396

140

2020

4564

962

854390

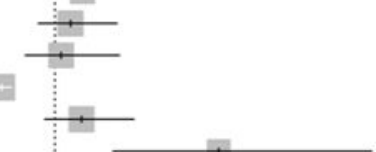

$+$

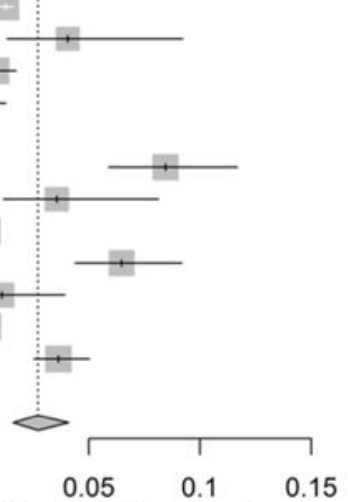

Male at Greater Risk Female at Greater Risk
Proportion

95\%-Cl Weight

$0.133[0.107 ; 0.163] \quad 4.9 \%$

$0.067[0.034 ; 0.116] \quad 4.3 \%$

$0.017[0.011 ; 0.026] \quad 5.1 \%$

$0.040[0.017 ; 0.077] \quad 4.4 \%$

$0.034[0.020 ; 0.055] \quad 4.9 \%$

$0.030[0.014 ; 0.056] \quad 4.7 \%$

$0.003[0.001 ; 0.008] \quad 5.1 \%$

$0.039[0.023 ; 0.063] \quad 4.8 \%$

$0.101[0.053 ; 0.170] \quad 4.0 \%$

$0.013[0.010 ; 0.016] \quad 5.2 \%$

$0.041[0.013 ; 0.092] \quad 4.0 \%$

$0.008[0.003 ; 0.017] \quad 5.0 \%$

$0.002[0.000 ; 0.013] \quad 4.8 \%$

$0.001[0.001 ; 0.001] \quad 5.2 \%$

$0.085[0.059 ; 0.117] \quad 4.8 \%$

$0.036[0.012 ; 0.081] \quad 4.2 \%$

$0.004[0.002 ; 0.008] \quad 5.1 \%$

$0.065[0.044 ; 0.092] \quad 4.8 \%$

$0.011[0.001 ; 0.039] \quad 4.4 \%$

$0.005[0.003 ; 0.007] \quad 5.2 \%$

$0.036[0.025 ; 0.050] \quad 5.0 \%$

$0.027[0.016 ; 0.041] 100.0 \%$

Figure 2.

Forest plot for the incidence proportion and 95\% CI of ACL injury in football players for men and women combined. 


\section{Author}

Faude et al,2005

Gilchrist et al,2008

Giza et al,2005

Hagglund et al,2009

Heidt et al,2000

Kiani et al,2010

LeGall et al,2008

Mandelbaum et al,2005

Ostenburg and Roos, 2000

Padua et al,2015

Pfeiffer et al,2006

Quisquater et al,2013

Soderman et al, 2000

Steffen et al,2008

Steffen et al,2016

Tegnander et al,2008

Walden et al,2011

Walden et al,2012

Random effects model

Heterogeneity: $I^{2}=97 \%, \tau^{2}=0.004, p<0.01$

\section{Number of ACL Injuries Female Population}

11
25
8
8
9
5
12
73
5
6
1
29
5
9
29
2
21
15

Figure 3.

Forest plot for incidence proportion and 95\% CI of ACL injury for female football players.
4564

55527

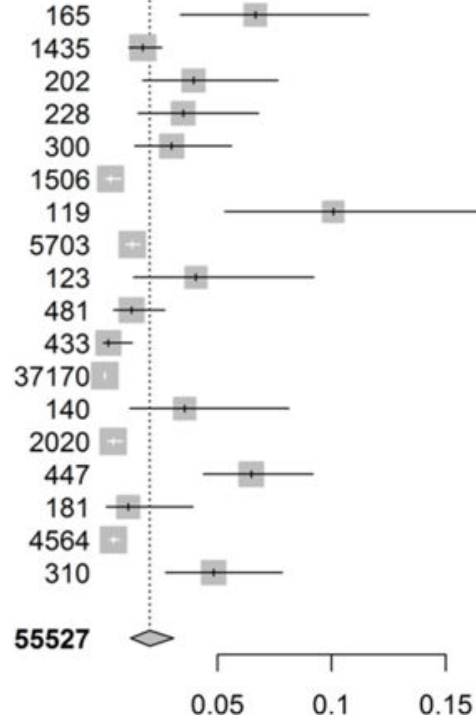

$0.017[0.011 ; 0.026] \quad 6.3 \%$

$0.040[0.017 ; 0.077] \quad 5.0 \%$

$0.035[0.015 ; 0.068] \quad 5.2 \%$

$0.030[0.014 ; 0.056] \quad 5.4 \%$

$0.003[0.001 ; 0.008] \quad 6.3 \%$

$0.101[0.053 ; 0.170] \quad 4.3 \%$

$0.013[0.010 ; 0.016] \quad 6.5 \%$

$0.041[0.013 ; 0.092] \quad 4.4 \%$

$0.012[0.005 ; 0.027] \quad 5.8 \%$

$0.002[0.000 ; 0.013] \quad 5.8 \%$

$0.001[0.001 ; 0.001] \quad 6.6 \%$

$0.036[0.012 ; 0.081] \quad 4.6 \%$

$0.004[0.002 ; 0.008] \quad 6.4 \%$

$0.065[0.044 ; 0.092] \quad 5.8 \%$

$0.011[0.001 ; 0.039] \quad 4.9 \%$

$0.005[0.003 ; 0.007] \quad 6.5 \%$

$0.048[0.027 ; 0.079] \quad 5.5 \%$

$0.020[0.012 ; 0.031] 100.0 \%$ 
Author

Caraffa et al,1996

Hagglund et al,2009

Krutsch et al,2016

Padua et al,2015

Quisquater et al,2013

Rahnama et al,2009

Walden et al,2011

Walden et al,2012

Random effects model

Heterogeneity: $I^{2}=99 \%, \tau^{2}=0.0213, p<0.01$
Number of ACL Injuries Total Males

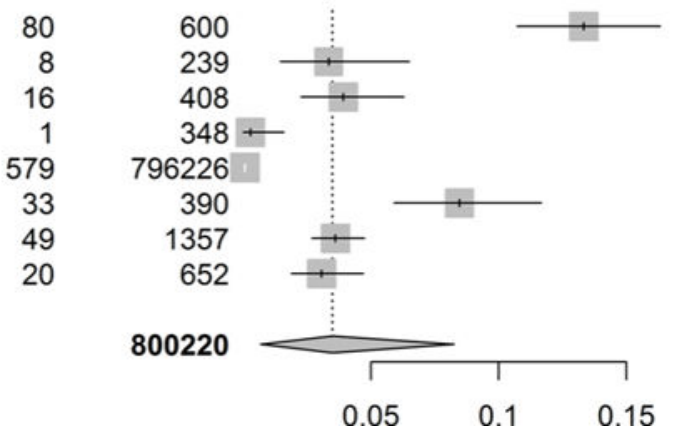

Proportion

$95 \%-\mathrm{Cl}$ Weight

$0.133[0.107 ; 0.163] 12.5 \%$

$0.033[0.015 ; 0.065] 12.2 \%$

$0.039[0.023 ; 0.063] 12.4 \%$

$0.003[0.000 ; 0.016] \quad 12.4 \%$

$0.001[0.001 ; 0.001] 12.8 \%$

$0.085[0.059 ; 0.117] \quad 12.4 \%$

$0.036[0.027 ; 0.047] \quad 12.7 \%$

$0.031[0.019 ; 0.047] \quad 12.6 \%$

$0.035[0.007 ; 0.082] 100.0 \%$

Figure 4.

Forest plot for incidence proportion and 95\% CI of ACL injury for male football players. 
Author

Hagglund et al,2009

Padua et al,2015

Quisquater et al,2013

Walden et al,2012

Random effects mode

Heterogeneity: $I^{2}=0 \%, \tau^{2}=0, p=0.47$
Famale Male

Number of ACL Injuries Population Number of ACL Injuries Population pulation

$\begin{array}{rr}\text { ries } & \text { Population } \\ 8 & 239 \\ 1 & 348 \\ 579 & 796226 \\ 20 & 652 \\ & 797465\end{array}$

$\begin{array}{rr}8 & 228 \\ 6 & 481 \\ 29 & 37170 \\ 15 & 310\end{array}$

38189
RR

$95 \%-\mathrm{Cl}$ Weight

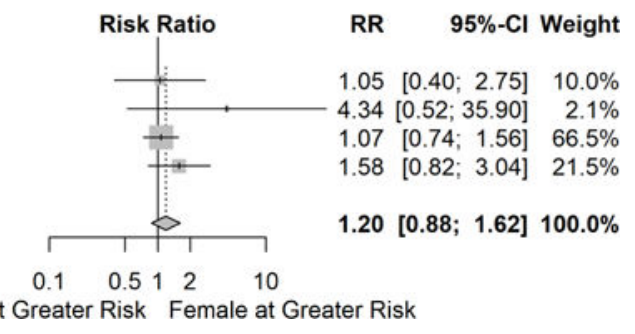

Figure 5.

Forest plot for RR and 95\% CI of ACL injury for football players-woman versus man. $<1=$ reduced RR in women; $>1=$ reduced RR in men. RR, relative risk. 


\section{Author}

Agel et al,2016

Beynnon et al,2014

Faude et al,2005

Gilchrist et al,2008

Giza et al,2005

Gwinn et al,2000

Hagglund et al,2009

Hewett et al,1999

Hootman et al,2007

Joseph et al,2013

Kiani et al,2010

Krutsch et al,2016

LeGall et al,2008

Mandelbaum et al,2005

Mountcastle et al,2007

Ostenburg and Roos,2000

Pfeiffer et al,2006

Soderman et al,2000

Stanley et al,2016

Steffen et al,2008

Tegnander et al,2008

Walden et al,2011

Walden et al,2012

Random effects model

Heterogeneity: $I^{2}=93 \%, \tau^{2}=0.2037, p<0.01$

Total Number of ACL Injuries Total Athlete Exposure/10000 Incidence Rate Rate $\quad 95 \%-C l$ Weight

97
35
11
25
8
53
16
3
579
140
5
16
12
73
353
3
1
5
157
9
2
21
35

136.0

29.0
1.8

1.8

17.8

21.5

6.3

2.2

333.5

170.1

6.7

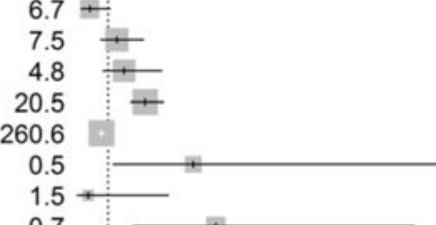

0.7

165.3

6.7

1.5

13.9

21.7

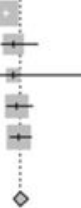

$0.71[0.58 ; 0.87] \quad 5.8 \%$

$1.21[0.87 ; 1.68] \quad 5.3 \%$

$6.11[3.38 ; 11.03] \quad 4.2 \%$

$2.84[1.92 ; 4.20] \quad 5.1 \%$

$0.45[0.22 ; 0.90] \quad 3.7 \%$

$2.47[1.88 ; 3.23] \quad 5.5 \%$

$2.54[1.56 ; 4.15] \quad 4.6 \%$

$1.36[0.44 ; 4.23] \quad 2.3 \%$

$1.74[1.60 ; 1.88] \quad 6.0 \%$

$0.82[0.70 ; 0.97] \quad 5.8 \%$

$0.75[0.31 ; 1.79] \quad 3.1 \%$

$2.13[1.31 ; 3.48] \quad 4.6 \%$

$2.50[1.42 ; 4.40] \quad 4.3 \%$

$3.56[2.83 ; 4.48] \quad 5.7 \%$

$1.35[1.22 ; 1.50] \quad 6.0 \%$

$6.00[1.94 ; 18.60] \quad 2.3 \%$

$0.67[0.09 ; 4.73] \quad 1.0 \%$

$7.14[2.97 ; 17.16] \quad 3.1 \%$

$0.95[0.81 ; 1.11] \quad 5.9 \%$

$1.34[0.70 ; 2.58] \quad 3.9 \%$

$1.33[0.33 ; 5.33] \quad 1.7 \%$

$1.51[0.99 ; 2.32] \quad 4.9 \%$

$1.61[1.16 ; 2.25] \quad 5.3 \%$

$1.69[1.36 ; 2.10] 100.0 \%$

Male at Greater Risk Female at Greater Risk

Figure 6.

Forest plot for total incidence rate and 95\% CI of ACL injury in football players for men and women combined. 


\section{Author}

Agel et al,2016

Beynnon et al,2014

Faude et al,2005

Gilchrist et al,2008

Giza et al,2005

Gwinn et al,2000

Hagglund et al,2009

Hewett et al,1999

Hootman et al,2007

Joseph et al,2013

Kiani et al,2010

LeGall et al,2008

Mandelbaum et al,2005

Mountcastle et al,2007

Ostenburg and Roos,2000

Pfeiffer et al,2006

Soderman et al,2000

Stanley et al,2016

Steffen et al,2008

Tegnander et al,2008

Walden et al,2011

Walden et al,2012

Random effects model

Heterogeneity: $I^{2}=91 \%, \tau^{2}=0.2736, p<0.01$
Number of Female ACL Injuries Athlete Exposure/10000 Incidence Rate Rate $\quad 95 \%-\mathrm{Cl}$ Weight

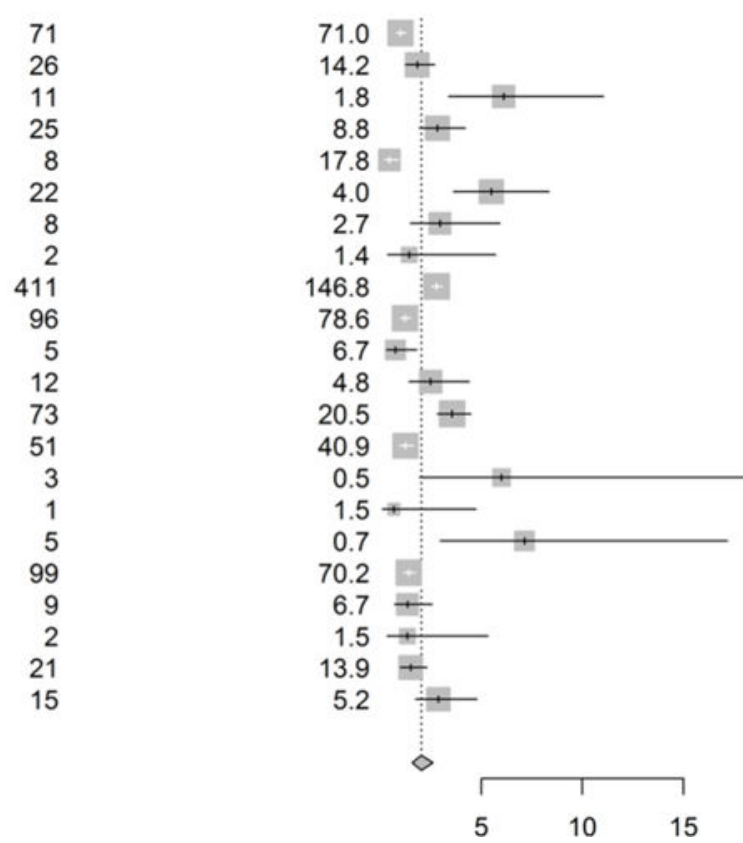

$1.00[0.79 ; 1.26] \quad 5.9 \%$

$1.83[1.25 ; 2.69] \quad 5.4 \%$

$6.11[3.38 ; 11.03] \quad 4.6 \%$

$2.84[1.92 ; 4.20] \quad 5.4 \%$

$0.45[0.22 ; 0.90] \quad 4.3 \%$

$5.50[3.62 ; 8.35] \quad 5.3 \%$

$1.43[0.36 ; 5.71] \quad 2.2 \%$

$2.80[2.54 ; 3.08] \quad 6.1 \%$

$1.22[1.00 ; 1.49] \quad 6.0 \%$

$0.75[0.31 ; 1.79] \quad 3.6 \%$

$2.50[1.42 ; 4.40] \quad 4.7 \%$

$3.56[2.83 ; 4.48] \quad 5.9 \%$

$1.25[0.95 ; 1.64] \quad 5.8 \%$

$6.00[1.94 ; 18.60] \quad 2.8 \%$

$0.67[0.09 ; 4.73] \quad 1.3 \%$

$7.14[2.97 ; 17.16] \quad 3.6 \%$

$1.41[1.16 ; 1.72] \quad 6.0 \%$

$1.34[0.70 ; 2.58] \quad 4.4 \%$

$1.33[0.33 ; 5.33] \quad 2.2 \%$

$1.51[0.99 ; 2.32] \quad 5.3 \%$

$2.88[1.74 ; 4.78] \quad 5.0 \%$

$2.03[1.57 ; 2.62] 100.0 \%$
$2.96[1.48 ; 5.92] \quad 4.3 \%$

Figure 7.

Forest plot for incidence rate and $95 \%$ CI of ACL injury for female football players. 
Montalvo et al.

Author

Agel et al,2016

Beynnon et al,2014

Gwinn et al,2000

Hagglund et al,2009

Hewett et al,1999

Hootman et al,2007

Joseph et al,2013

Krutsch et al,2016

Mountcastle et al,2007

Stanley et al,2016

Walden et al,2012

Random effects model

Heterogeneity: $I^{2}=92 \%, \tau^{2}=0.2172, p<0.01$
Page 22

Number of Male ACL Injuries Athlete Exposure/10000 Incidence Rate $\quad$ Rate $\quad 95 \%-C l$ Weight

26
9
31
8
1
168
44
16
302
58
20

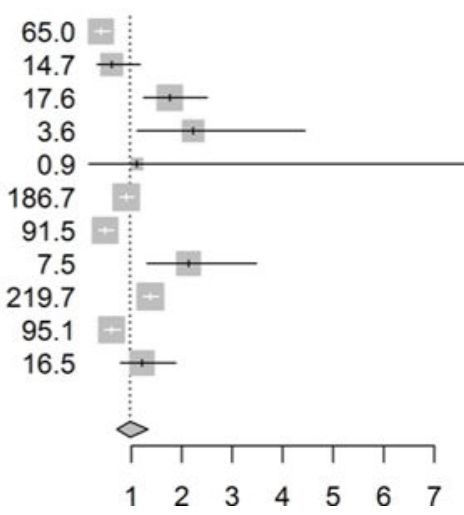

$0.40[0.27 ; 0.59] \quad 9.9 \%$

$0.61[0.32 ; 1.18] \quad 7.7 \%$

$1.76[1.24 ; 2.50] \quad 10.2 \%$

$2.22[1.11 ; 4.44] \quad 7.4 \%$

$1.11[0.16 ; 7.89] \quad 2.1 \%$

$0.90[0.77 ; 1.05] \quad 11.4 \%$

$0.48[0.36 ; 0.65] \quad 10.6 \%$

$2.13[1.31 ; 3.48] \quad 9.1 \%$

$1.37[1.23 ; 1.54] \quad 11.5 \%$

$0.61[0.47 ; 0.79] \quad 10.8 \%$

$1.21[0.78 ; 1.88] \quad 9.5 \%$

$0.97[0.71 ; 1.33] 100.0 \%$

Figure 8.

Forest plot for incidence rate and 95\% CI of ACL injury for male football players. 
Author

Agel et al,2016 Beynnon et al, 2014

Gwinn et al,2000

Hagglund et al,2009

Hewett et al,1999

Hootman et al,2007

Joseph et al,2013

Mountcastle et al,2007

Stanley et al,2016

Walden et al,2012

Random effects model

Heterogeneity: $I^{2}=83 \%, \tau^{2}=0.2017, p<0.01$

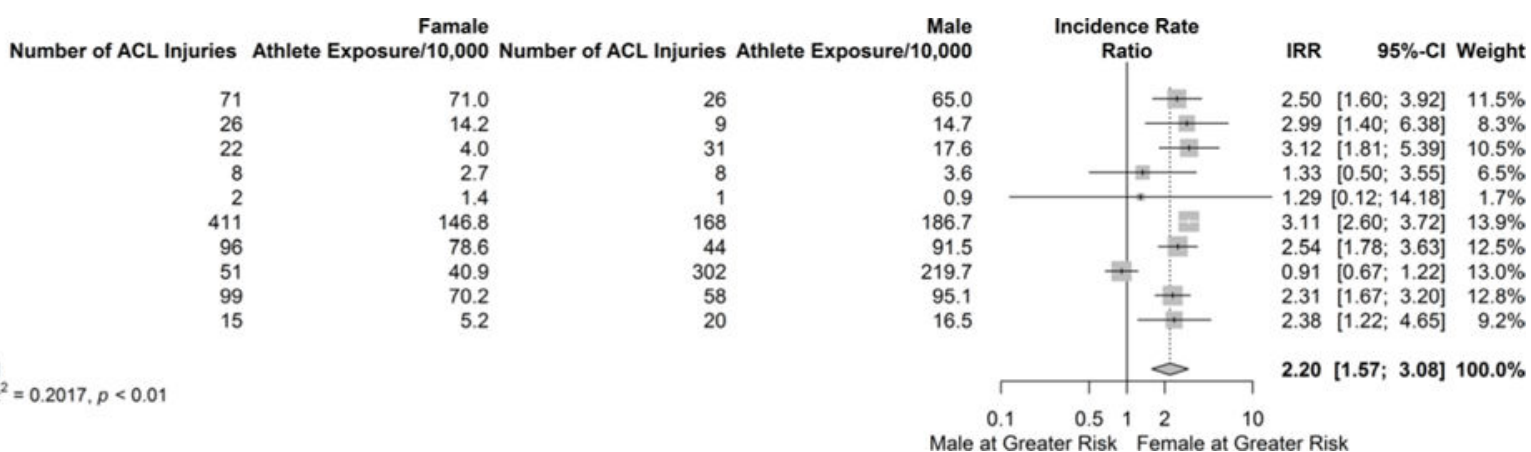

Figure 9.

Forest plot for incidence rate and $95 \%$ CI of ACL injury for football players-woman versus man. $<1=$ reduced relative risk in women; $>1=$ reduced relative risk in men. IRR, incidence rate ratio. 


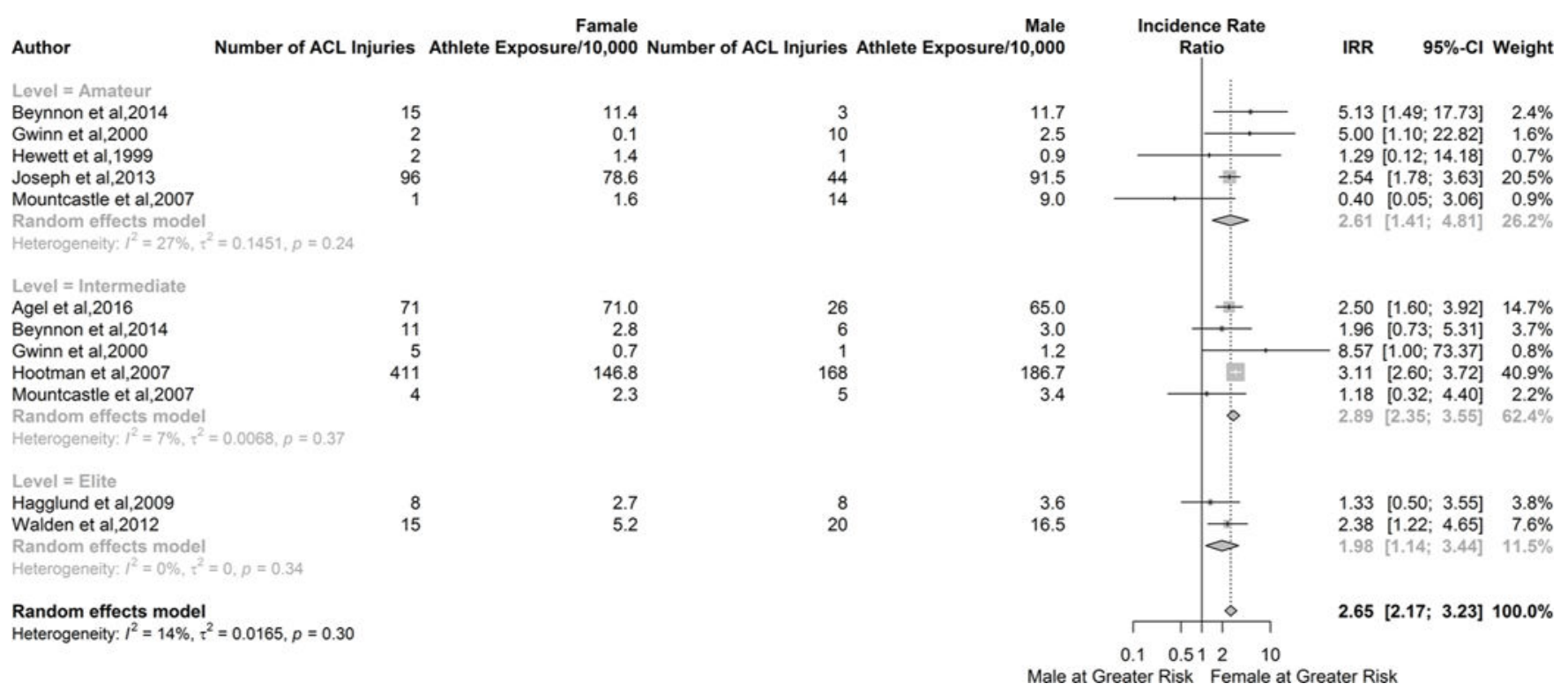

Figure 10.

Forest plot for incidence rate and 95\% CI of ACL injury in football players-woman versus man by participation level. $<1=$ reduced relative risk in women; $>1=$ reduced relative risk in men. IRR, incidence rate ratio. 
Study

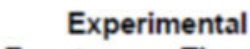

After2007 = 2

Agel et al

Gwinn et al

Joseph et al

Stanley et al

Walden et al

Fixed effect model

Random effects model

Heterogeneity: $\tau^{2}=0 \%, \tau^{2}=0, p=0.92$

After2007 = 1

Beynnon et al

Hagglund et al

Hewett et al

Hootman et al

Mountcastle et al

Fixed effect model

Random effects model

Heterogeneity: $I^{2}=92 \%, \tau^{2}=0.5715, p<0.01$

Fixed effect model

Random effects model

Heterogeneity: $I^{2}=83 \%, \tau^{2}=0.2026, p<0.01$
$26 \quad 14.21920$

$8 \quad 2.70780$

21.35340

411146.78571

$51 \quad 40.92230$

$\begin{array}{lr}9 & 14.73810\end{array}$

83.56805

$1 \quad 0.85130$

168186.66667

302219.68120
Control
Time

$26 \quad 65.00000$

$31 \quad 17.56280$

$44 \quad 91.45510$

$\begin{array}{ll}58 & 95.08197\end{array}$

$20 \quad 16.49230$

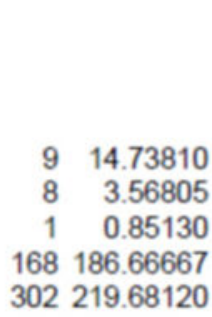

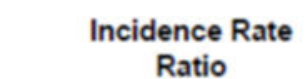

Ratio
IRR

Weight Weight
$95 \%-\mathrm{Cl}$ (fixed) (random)
$2.50[1.60 ; 3.92] \quad 6.8 \% \quad 11.5 \%$

$3.16[1.83 ; 5.45] \quad 2.9 \% \quad 10.5 \%$

$2.54[1.78 ; 3.63] \quad 10.2 \% \quad 12.5 \%$

$2.31[1.67 ; 3.20] \quad 12.4 \% \quad 12.8 \%$

$2.36[1.21 ; 4.61] \quad 2.4 \% \quad 9.2 \%$

$2.49[2.06 ; 3.01] \quad 34.7 \% \quad-$

$2.50[2.07 ; 3.02] \quad-\quad 56.5 \%$

$2.99[1.40 ; 6.39] \quad 2.2 \% \quad 8.3 \%$

$1.32[0.49 ; 3.51] \quad 1.7 \% \quad 6.5 \%$

$1.26[0.11 ; 13.87] \quad 0.3 \% \quad 1.7 \%$

$3.11[2.60 ; 3.72] \quad 37.2 \% \quad 13.9 \%$

$0.91[0.67 ; 1.22] \quad 23.8 \% \quad 13.0 \%$

$2.25[1.95 ; 2.59] \quad 65.3 \% \quad-$

$1.78[0.83 ; 3.85]-43.5 \%$

2.33 [2.08; 2.61] $100.0 \%$ $2.20[1.57 ; 3.07] \quad-\quad 100.0 \%$

Figure 11.

Forest plot for incidence rate and 95\% CI of ACL injury in football players-woman versus man by year of publication. $<1=$ reduced relative risk in women; $>1=$ reduced relative risk in men. IRR, incidence rate ratio.

Br J Sports Med. Author manuscript; available in PMC 2019 November 01. 